\title{
O ESTADO DA ARTE SOBRE SISTEMA SOCIOEDUCATIVO NO BRASIL (2006 - 2016)
}

\author{
THE STATE OF THE ART ON SOCIO-EDUCATIONAL SYSTEM IN BRAZIL \\ (2006 - 2016)
}

\begin{abstract}
Julio Cesar Francisco
Doutorando em Educação pela Universidade Federal de São Carlos, São Carlos, São Paulo, Brasil, com período sanduíche no Conservatoire National des Arts et Métiers - CNAM, Paris/França. Bolsista da Fundação de Amparo à Pesquisa do Estado de São Paulo - FAPESP (2018-2021).

socioeducativo.julio@gmail.com
\end{abstract}

Roseli Esquerdo Lopes

Doutora em Educação pela Universidade Estadual de Campinas. Professora Titular do Departamento de Terapia Ocupacional e dos Programas de Pós-Graduação em Educação e em Terapia Ocupacional da Universidade Federal de São Carlos, São Carlos, São Paulo, Brasil. relopes@ufscar.br

\begin{abstract}
Resumo: Neste artigo, apresenta-se um estudo de revisão da literatura, que buscou apreender a natureza dos aportes acadêmico-científicos no debate do Sistema Socioeducativo no Brasil. Para tanto, foram levantadas dissertações e teses na Biblioteca Digital de Teses e Dissertações (BDTD), do Instituto Brasileiro de Informação Científica e Tecnológica (IBICT), e artigos publicados em periódicos do estrato A1 do Qualis-Periódicos, conforme parâmetros da área de Educação da Coordenação de Aperfeiçoamento de Pessoal de Nível Superior (CAPES) para o quadriênio 2013-2016. Da sistematização e da análise da produção acadêmica, resultou uma síntese analítica das principais conclusões, com destaque para três aspectos: variedade de universidades e orientadores imbricados em pesquisas na Pós-Graduação que envolvem a situação de jovens e adolescentes em conflito com a lei e submetidos a medidas socioeducativas; viés empírico e qualitativo das pesquisas publicadas, tanto nos periódicos quanto em dissertações e teses; fragilidades familiares e problemáticas escolares como situações de vulnerabilidade associadas ao crescimento dos atos infracionais.
\end{abstract}

Palavras-chave: Ato infracional. Jovens e juventudes. Sistema socioeducativo.

\begin{abstract}
In this paper, a literature review study is presented, which sought to apprehend the nature of academicscientific contributions in the debate of the Socio-educational System in Brazil. For this purpose, dissertations and theses from the Digital Library of Theses and Dissertations (Biblioteca Digital de Teses e Dissertações - BDTD) of the Brazilian Institute of Scientific and Technological Information (Instituto Brasileiro de Informação Científica e Tecnológica - IBICT) and the papers published in journals of the A1 strand of Qualis-Journals, according to parameters of the area of Education of the Coordination for the Improvement of Higher Education Personnel (CAPES) for the 2013-2016 quadrennium were collected. From the systematization and analysis of academic production, an analytical synthesis of the main conclusions resulted, with emphasis on three aspects: variety of universities and supervisors involved in Graduate Programs research that involve the situation of young people and adolescents in conflict with the law and subjected to socio-educational measures; empirical and qualitative bias of published research, both in journals and in dissertations and theses; family weaknesses and school problems as situations of vulnerability associated with the growth of infractions.
\end{abstract}

Keywords: Infraction act. Young people and youth. Socio-educational system.

\section{Para citar - (ABNT NBR 6023:2018)}

FRANCISCO, Julio Cesar; LOPES, Roseli Esquerdo. O Estado da arte sobre sistema socioeducativo no Brasil (2006 - 2016) Eccos - Revista Cientifica, São Paulo, n. 52, p. 1-22, e11592, jan./mar. 2020. Disponível em: https://doi.org/10.5585/eccos.n52.11592. 


\section{Introdução}

O presente estudo, de cunho bibliográfico, integra uma pesquisa de Doutorado ${ }^{1}$ mais ampla, em andamento, intitulada Funcionamento Interinstitucional do Sistema Socioeducativo no Município de São Carlos, cujo objetivo central é analisar o funcionamento interinstitucional no atendimento inicial ao adolescente ao qual se atribui autoria de ato infracional, tendo em vista colaborar com políticas públicas que possam minimizar as violências.

Para a composição do referencial teórico que incide na análise dos dados da referida pesquisa, foram empreendidos esforços cujos resultados são trazidos neste artigo: sistematização da produção acadêmica no formato de teses, de dissertações e de artigos em periódicos, bem como de pesquisadores e suas Instituições de Educação Superior (IES), vinculadas às investigações e as principais conclusões desses produtos sobre a temática do adolescente em conflito com a lei.

Dado o interesse/objeto que guia a pesquisa citada, deu-se atenção especial às produções que tratam do funcionamento das instituições que fazem a apuração dos atos infracionais e compõem o Sistema Socioeducativo no Brasil, ou de similares no exterior. Todavia, foram poucos os estudos encontrados que se voltavam para esse momento do trabalho socioeducativo, o que parece demonstrar a necessidade de pesquisas e maior conhecimento sobre os dilemas do Sistema que atende a adolescentes acusados de infringir a lei. Importa ressaltar que a palavra "Sistema" e sua operacionalização, antes das primeiras elaborações do Sistema Nacional de Atendimento Socioeducativo (SINASE), em 2006 (BRASIL, 2006), não apareceu em nenhuma outra legislação voltada a inimputáveis durante a história do Brasil, o que pode ser comprovado pela análise dos dois únicos códigos de menores (Lei № 4.242, de 5 de janeiro de 1921, alterada pelo Decreto $\mathrm{N}^{\mathrm{o}} 17.943-\mathrm{A}$, de 12 de outubro de 1927, e Lei $\mathrm{N}^{\circ} 6.697$, de 10 de outubro de 1979, que substitui a anterior).

O Sistema referido está voltado para atender a diferentes situações de adolescentes e jovens em conflito com a lei, submetidos às instâncias oficiais do Estado. Nele se pressupõe um agir sistemático que envolve diferentes agentes públicos que compõem estrategicamente operações integradas, visando alcançar, de forma conjunta, um mesmo objetivo. As instituições envolvidas nessa ação do Estado são Ministério Público, Poder Judiciário, Segurança Pública, Defensoria Pública e executores das medidas socioeducativas, em articulação, como seria desejável, com as políticas setoriais dos municípios, conforme Art. 88, inciso V, do Estatuto da Criança e do Adolescente (ECA) - Lei No 8.069, de 13 de julho de 1990 (BRASIL, 1990). 
Por um lado, do levantamento bibliográfico realizado para a composição deste estado da arte, pode-se inferir que poucos foram os trabalhos sobre a temporalidade da apuração das infrações; por outro lado, muitas (relativamente) são as pesquisas e os pesquisadores que se debruçaram sobre a relação entre o adolescente e o ato infracional, bem como sobre o processo de escolarização desses sujeitos e as vulnerabilidades a que estão suscetíveis nas famílias e nos territórios de existência, que, muitas vezes, constituem espaços de socialização pelos quais também circulam e/ou nos quais são bastante presentes ações ilícitas.

Destarte, o material deste artigo está dividido em quatro partes que estabelecem relações entre si, quais sejam: I. Procedimentos metodológicos empregados na pesquisa; II. Resultados obtidos; III. Discussão dos principais resultados, no que se refere aos aportes pretendidos para a ação no campo do Sistema Socioeducativo; e IV. Considerações finais.

\section{Metodologia}

A pesquisa bibliográfica empreendida buscou localizar e sistematizar as principais produções acadêmicas, seus autores(as) e resultados mais significativos de investigação sobre o Sistema Socioeducativo no Brasil. Para tanto, foram levantadas e analisadas dissertações e teses constantes na Biblioteca Digital de Teses e Dissertações (BDTD) do Instituto Brasileiro de Informação Científica e Tecnológica (IBICT) produzidas entre os anos 2006 (quando da aprovação do SINASE) e 2016 (ano anterior à coleta, que se deu em 2017), bem como os artigos publicados (2006-2016) em periódicos do estrato A1 do Qualis'1-Periódicos, conforme parâmetros da área de Educação da Coordenação de Aperfeiçoamento de Pessoal de Nível Superior (CAPES) para o quadriênio 2013-2016.

No que diz respeito às produções dos Programas de Pós-Graduação da plataforma BDTD, para fazer um recorte mais claro e confiável do universo, decidiu-se por levantar e organizar sistematicamente as fontes resultantes de pesquisa nas áreas de Educação, Serviço Social, Psicologia e Sociologia ${ }^{2}$, o que resultou em um conjunto de teses e dissertações de autores(as) (discentes de Pós-Graduação) e orientadores(as) implicados(as) na produção de conhecimento sobre as problemáticas que envolvem adolescentes em conflito com a lei no Brasil.

Para abranger o maior número possível de teses e de dissertações, utilizaram-se três descritores: Ato Infracional, Medida Socioeducativa e Sistema Socioeducativo, a partir de sua presença nos campos "título", "palavras-chave" e "resumo". A seleção dos artigos, circunscrita 
apenas à área da educação, ocorreu pela delimitação dos estratos dos periódicos e pela leitura de "títulos", "resumos" e "palavras-chave", de modo a selecionar os textos relacionados à temática em tela. Para a composição do corpus de análise, foram lidas introdução, metodologia e resultados apresentados nos produtos acadêmicos encontrados.

Os resultados auferidos foram discutidos e analisados a partir de Bourdieu (2014), Piaget (1994), Sennett (2004) e Lukács (2013); e de obras de especialistas na temática das juventudes e do campo do Sistema Socioeducativo, a saber: Sposito (2008), Volpi (2015), Souza (2009) e Lima (2013). Insta destacar que a metodologia é sustentada na abordagem compreensiva do fenômeno social, de base materialista histórico-dialética.

Esses procedimentos possibilitaram verificar a pertinência e a aderência do objeto de estudo, como também recuperar, na fonte e na íntegra, os exemplares para leitura e sistematização, com atenção especial à política de atendimento socioeducativo e ao funcionamento, entre as instituições, do processo de apuração do ato infracional, recuperando depoimentos, problemáticas e proposições trazidas e o que vem se colocando como temas e abordagens desafiantes para o campo do Sistema Socioeducativo brasileiro.

Assim, a partir do acesso às teses e às dissertações do BDTD e aos artigos de periódicos Qualis A1 da área da Educação ${ }^{3}$, pretendeu-se contribuir com a discussão veiculada pelo livro intitulado $O$ estado da arte sobre juventude na pós-graduação brasileira, especificamente em relação ao capítulo “Adolescentes em processos de exclusão” (SPOSITO, 2009).

\section{Resultados}

Entre os trabalhos selecionados, a maioria (44) foi desenvolvida na Pontifícia Universidade Católica - PUC (em diferentes regiões do Brasil), seguida pela Universidade de Brasília - UnB (13), Universidade Estadual Paulista - Unesp (12), Universidade de São Paulo USP (12), Universidade Federal do Rio Grande do Sul - UFRGS (9) e Universidade Federal de São Carlos - UFSCar (9), entre outras Instituições de Ensino Superior (IES), como se pode observar no Quadro 1. 
Quadro 1 - Dissertações e Teses sobre Sistema Socioeducativo, por IES (2006-2016)

\begin{tabular}{|l|r|r|c|}
\hline \multicolumn{1}{|c|}{ IES } & Dissertações & Teses & Total \\
\hline Pontifícia Universidade Católica - PUC & 35 & 9 & 44 \\
\hline Universidade de Brasília - UnB & 10 & 3 & 13 \\
\hline Universidade Estadual Paulista - UNESP & 8 & 4 & 12 \\
\hline Universidade de São Paulo - USP & 5 & 7 & 12 \\
\hline Universidade Federal do Rio Grande do Sul - UFRGS & 5 & 4 & 9 \\
\hline Universidade Federal de São Carlos - UFSCar & 5 & 4 & 9 \\
\hline Universidade Federal do Rio Grande do Norte - UFRN & 6 & 0 & 6 \\
\hline Universidade Estadual de Londrina - UEL & 5 & 1 & 6 \\
\hline Universidade do Estado do Rio de Janeiro - UERJ & 3 & 3 & 6 \\
\hline Universidade Federal de Minas Gerais - UFMG & 3 & 2 & 5 \\
\hline Universidade Federal de Santa Catarina - UFSC & 4 & 0 & 4 \\
\hline Universidade Federal do Amazonas - UFAM & 4 & 0 & 4 \\
\hline Outras & 10 & 6 & 16 \\
\hline TOTAL & $\mathbf{1 0 3}$ & $\mathbf{4 3}$ & $\mathbf{1 4 6}$ \\
\hline
\end{tabular}

Fonte: Elaborado pelos autores com base nos dados coletados na BDTD/IBICT, 2017.

As pesquisas sobre Sistema Socioeducativo têm tido uma boa recepção em três principais áreas do conhecimento das quatro selecionadas, com destaque para a área de Psicologia, que concentra 49 trabalhos $(33,56 \%)$, conforme mostra o Quadro 2. Em relação às demais, o tema aparece em 45 estudos na área do Serviço Social (30,82\%), seguido de perto pela área da Educação (42 estudos - 28,76\%) e, com mais distância, a Sociologia, com apenas 10 estudos $(6,85 \%)$.

Quadro 2 - Distribuição de Dissertações e Teses sobre Sistema Socioeducativo, por áreas de conhecimento (2006-2016)

\begin{tabular}{|c|c|c|c|}
\hline \multirow{2}{*}{ Área do conhecimento } & \multicolumn{3}{|c|}{$\mathbf{N}^{\mathbf{0}}$ de trabalhos } \\
\cline { 2 - 4 } & Dissertações & Teses & Total \\
\hline Psicologia & 33 & 16 & 49 \\
\hline Serviço Social & 37 & 8 & 45 \\
\hline Educação & 28 & 14 & 42 \\
\hline Sociologia & 5 & 5 & 10 \\
\hline TOTAL & 103 & 43 & 146 \\
\hline
\end{tabular}

Fonte: Elaborado pelos autores com base nos dados coletados na BDTD/IBICT, 2017.

Nesses produtos, verifica-se predominância de estudos sobre a situação infracional e a relação com a escola dos adolescentes, sobretudo nas pesquisas em nível de Mestrado. No acompanhamento dessas pesquisas, constata-se uma quantidade diversificada de orientadores (Quadro 3), os quais são referências importantes na produção de conhecimento na Pós- 
Graduação. Esses dados permitem perceber um locus de concentração de pesquisas nesse campo, pontuando a relação pobreza, família e escola como fatores para o envolvimento com a situação infracional.

Quadro 3 - Orientadores de dois ou mais estudos sobre Sistema Socioeducativo, por áreas de conhecimento e IES (2006-2016)

\begin{tabular}{|c|l|c|c|c|}
\hline $\mathbf{N}^{\mathbf{0}}$ & \multicolumn{1}{|c|}{ Orientador(a) } & $\begin{array}{c}\text { Teses - } \\
\text { Dissertações }\end{array}$ & Área & IES \\
\hline 1 & Elenice Maria Cammarosano Onofre & 5 & Educação & UFSCar \\
\hline 2 & Beatriz Gershenson Aguinsky & 5 & Serviço Social & PUC - RS \\
\hline 3 & Myrian Veras Baptista & 4 & Serviço Social & PUC - SP \\
\hline 4 & Denise Carmen de Andrade Neves & 4 & Serviço Social & PUC - GO \\
\hline 5 & Marcos César Alvarez & 3 & Sociologia & USP \\
\hline 6 & Denise Câmara Carvalho & 2 & Serviço Social & UFRN \\
\hline 7 & Carmen Maria Craidy & 2 & Educação & UFRGS \\
\hline 8 & Débora Diniz & 2 & Serviço Social & UNB \\
\hline 9 & Maria Inês Assumpção Fernandes & 2 & Psicologia & USP \\
\hline 10 & Ana Lúcia Galinkin & 2 & Psicologia & UNB \\
\hline 11 & Maria Lúcia Martinelli & 2 & Serviço Social & PUC - SP \\
\hline 12 & Ilama Lemos Paiva & 2 & Psicologia & UFRN \\
\hline 13 & Ana Cristina Resende & 2 & Psicologia & PUC - GO \\
\hline 14 & Irene Rizzini & 2 & Serviço Social & PUC - RIO \\
\hline 15 & José Fernando Siqueira Silva & Serviço Social & UNESP \\
\hline 16 & Marli Palma Souza & Serviço Social & UFSC \\
\hline 17 & Maria Cristina Vicentin & Psicologia & PUC - SP \\
\hline
\end{tabular}

Fonte: Elaborado pelos autores com base nos dados coletados na BDTD/IBICT, 2017.

Embora as teses e as dissertações sejam importantes, os artigos tendem a ter maior circulação e impacto no meio acadêmico e têm sido um fator destacado na avaliação de pesquisadores e de Programas de Pós-Graduação, especialmente quando publicados em periódicos situados em estratos superiores do sistema Qualis da CAPES de qualificação de revistas científicas, conforme os critérios utilizados para o triênio 2013-2016. Assim, abarcando um número maior de produções, para além das pesquisas de pós-graduandos, analisou-se também um recorte dos artigos publicados nas revistas cientificas da área de Educação. Entre 2006 e 2016, dos 23 periódicos dessa área pertencentes ao estrato A1, obteve-se 91 publicações sobre a temática. Desse montante, 63,73\% estão concentradas nos periódicos Psicologia: Teoria e Pesquisa (14 artigos), História Ciência e Saúde (13), Educação \& Realidade (12 artigos), Paidéia (10 artigos) e Psicologia: Reflexão e Crítica (9 artigos) ${ }^{4}$. 
No conjunto das produções reunidas, observando-se a epistemologia presente ou não nas pesquisas, buscou-se identificar aquela que orientou as teses, as dissertações e os artigos, o que levou à constatação de uma pluralidade de perspectivas, a saber: marxistas (materialistashistóricas), humanistas-existenciais, fenomenológicas, tradicionais ${ }^{5}$ e pós-modernas ${ }^{6}$. Atados a esses diferentes referenciais, houve três principais recorrências do tipo de abordagem para apreender o objeto pesquisado, constituídas por: pesquisa documental, bibliográfica e trabalho de campo (aplicação de entrevistas e observações participantes). Esses três tipos de abordagem, em vários casos, articularam-se para a compreensão do problema de pesquisa, conforme se pode verificar no Quadro 4.

Quadro 4 - Perfil do quadro epistemológico de referência das pesquisas e publicações sobre Sistema Socioeducativo

\begin{tabular}{|l|r|r|r|r|}
\hline \multicolumn{1}{|c|}{ Referencial teórico } & Dissertações & \multicolumn{1}{c|}{ Teses } & \multicolumn{1}{c|}{ Artigos } & \multicolumn{1}{c|}{ Total } \\
\hline Marxistas & 34 & 14 & 7 & 55 \\
\hline Pós-modernas & 19 & 4 & 6 & 29 \\
\hline Humanista-existenciais & 2 & 0 & 0 & 2 \\
\hline Tradicionais & 7 & 5 & 3 & 15 \\
\hline Fenomenológicas & 10 & 2 & 3 & 15 \\
\hline Não descreve a epistemologia adotada & 31 & 18 & 72 & 121 \\
\hline Procedimentos metodológicos & & & & \\
\hline Trabalho de campo & 76 & 36 & 48 & 160 \\
\hline Pesquisa documental & 28 & 18 & 24 & 70 \\
\hline Revisão bibliográfica & 26 & 10 & 22 & 48 \\
\hline Pesquisa (Auto)biográfica & 0 & 0 & 1 & 1 \\
\hline Relato de Experiência & 0 & 0 & 2 & 2 \\
\hline Entrevista & 0 & 0 & & 1 \\
\hline Tipo de análise & & & & \\
\hline Quantitativa & 1 & 2 & 5 & 8 \\
\hline Qualitativa & 82 & 36 & 71 & 189 \\
\hline Mista - quanti-qualitativa & 9 & 3 & 15 & 27 \\
\hline
\end{tabular}

Fonte: Elaborado pelos autores com base nos dados coletados no Qualis CAPES periódicos, 2017.

As pesquisas ${ }^{7}$ concentram-se em análises de práticas por meio de estudos de caso $(56,73 \%)$, em que se empregam estratégias metodológicas como observações de campo, descrições de práticas sociais e aplicações de entrevistas, assumindo o viés qualitativo $(84,37 \%)$ e se utilizando, em grande medida, de análise de conteúdo ou de discurso. Por sua vez, as referências teóricas destacadas vinculam-se às tendências marxistas $(23,20 \%)$ e pós-modernas (12,23\%), com uma quantidade significativa de trabalhos que não assumem nenhuma posição teórica específica $(51,05 \%)$, concentrando-se na apresentação de resultados de pesquisa. 


\section{Discussão}

Da leitura e da sistematização de todos os produtos reunidos (dissertações, teses e artigos), foi possível dividi-los em sete subtemas inter-relacionados: 1) Adolescentes e família; 2) Adolescentes e violência; 3) Juventudes e escolarização; 4) Adolescentes e processo de ensino em ambientes de privação de liberdade; 5) Políticas de atendimento socioeducativo; 6) Adolescentes egressos de medida socioeducativa; 7) Problemas psicossociais em adolescentes em conflito com a lei.

Pode-se destacar que o conjunto dos produtos de dissertações, de teses e de artigos, somado a alguns produtos dos orientadores como referências dos campos da Sociologia, do Serviço Social, da Educação e da Psicologia, cada qual a seu modo, converge, em alguma medida, para o entendimento de que a relação entre o adolescente e o ato infracional está marcada por vulnerabilidades e fatores de exclusão (LASARETTO, 2009; ALBUQUERQUE, 2015; COSTA JUNIOR, 2012; CAFFAGNI, 2012; MENESES, 2006; BERNARDO, 2011; RIZZINI, 2000; BARROS, 2015; MEDEIROS, 2015; BORBA; LOPES; MALFITANO, 2015), especialmente dentro das famílias, que não encontram formas de socialização dos filhos para uma educação que consiga ofertar parâmetros e limites (PIAGET, 1994), que levem ao respeito (SENNETT, 2004). Ademais, as famílias e os adolescentes envolvidos com o "mundo do crime" não conseguem frear as necessidades incorporadas decorrentes da sociedade do consumo (de mercadorias em distintas formas), que encontra sua fonte difusora na mídia, nas redes sociais e nas contradições do capitalismo (ALBUQUERQUE, 2015). Nesse escopo, para Conte:

\footnotetext{
O ato violento convoca as instâncias de referência que hoje estão amortecidas, céticas, desconfiadas frente a um adolescente, em geral, desamparado. Com o triunfo do individualismo, resta ao jovem expressar de forma radical a tentativa de se fazer exceção em um tempo em que todo mundo quer as mesmas coisas. A delinquiência coloca em questão a existência do sujeito no qual o ser está como equivalência do delinqüir. $\mathrm{O}$ adolescente sofre porque, teoricamente, pode escolher o que quiser, sem anteparos, sem um olhar e uma voz que o reconheça como eu e que ele valorize. (CONTE, 2008, p. 133).
}

Assim, tem-se uma dinâmica social que é estruturalmente desigual entre as classes sociais, em que os objetos têm mais valor do que a própria vida e, como consequência, há uma produção de novas contradições humanas pela banalização da violência, em suas várias configurações.

Além de tudo isso, entre os adolescentes que ingressam no Sistema Socioeducativo, há dificuldades de ordem afetiva e social que prejudicam a aproximação e os vínculos com os seus 
familiares. A ruptura dos laços familiares é recorrente nesses contextos (MENESES, 2006; VIEIRA, 2015) e ocasiona um prejuízo grande para a socialização. De acordo com Lasaretto,

[...] os adolescentes muitas vezes são abandonados pela família ou descuidados pelos pais, que nem sempre oferecem afeto, valores e regras aos filhos. Isso gera a falta de transmissão de valores morais [...], assim como demonstração de carinho, afeto e preocupação. Além disso, as perspectivas econômicas nem sempre são favoráveis, deixando-os longe do que a sociedade do consumo exalta. Ao chegar à escola, a falta de atrativos em uma educação decadente traz desmotivação e o adolescente busca outros entretenimentos, como brincadeiras que o faz ser indesejado naquele ambiente. Ao invés de ser chamado à realidade escolar, passa a ser excluído, e essa exclusão fará com que ele caia no índice de analfabetismo e, consequentemente, de desemprego, o que gera uma exclusão social intensa. (LASARETTO, 2009, p. 108-109).

Esses aspectos acabam por reforçar justamente aquilo que se quer combater: a aproximação dos jovens com grupos inseridos no "mundo do crime" (LASARETTO, 2009; COSTA JUNIOR, 2012; MENESES, 2006; BARROS, 2015; MEDEIROS, 2015; MARINHO, 2013). Encontra-se, nas infrações, principalmente as que envolvem tráfico e roubo, uma saída momentânea/imediata para ostentar poder, status e reconhecimento, supostamente adquiridos em formas de bens e serviços vendidos/trocados (porém não acessíveis a todos) dentro do modelo produtivo vigente (SILVA, 2003). Além das aquisições momentâneas, há uma vontade de controlar a própria vida, pela satisfação duradoura das necessidades de sobrevivência e de existência do ser social, o que pode provocar, frente às desigualdades na distribuição de propriedade e de bens produzidos na relação entre seres humanos e natureza, a violência exacerbada (LUKÁCS, 2013).

Atrelado a esses fatores, tem-se uma escola pública que exclui o adolescente tido como problemático, produto desse próprio meio social injusto (ALBUQUERQUE, 2015; BARROS, 2015; BORBA; LOPES; MALFITANO, 2015), mormente quando é egresso de medida socioeducativa, alegando que são pessoas que desencadeiam confusões, violência e atrapalham o ensino dos demais (PADOVANI; RISTUM, 2013). Tanto é que a maioria das pesquisas descreve que, no momento da apreensão, os adolescentes geralmente estão fora da escola, ou em anos escolares fora da sua idade ideal ou sofreram expulsões e reprovações constantes (COSTA JUNIOR, 2012; FRANCISCO, 2017; BARROS, 2015; BORBA; LOPES; MALFITANO, 2015; PADOVANI; RISTUM, 2013).

Historicamente, a escola foi implantada e progressivamente difundida de maneira degradada aos novos usuários (SPOSITO, 2008), no sentido de atender às demandas mínimas da população, por meio do ensino público, como instrumento de controle social e de reposição 
barata de pessoal no mercado de trabalho, principalmente em cargos informais (BARROS, 2015), inferiores, de baixa remuneração e de pouco prestígio social.

Na mesma proporção que a escola exclui, o jovem também acaba por excluí-la, corroborando para um desrespeito mútuo (SENNETT, 2004), que ocasiona a subtração de hábitos e de rotinas escolares (PADOVANI; RISTUM, 2013; FRANCISCO, 2017; LASARETTO, 2009; ALBUQUERQUE, 2015). Essas conjunturas agravam ou levam às ações de violência, impulsionam problemas psicológicos e de relacionamento sociofamiliar, além da obviedade de entrar em conflito com os preceitos jurídicos (LASARETTO, 2009; COSTA JUNIOR, 2012; MENESES, 2006; MEDEIROS, 2015; VIEIRA, 2015). Assim, explica-se em parte o fenômeno da violência entre educador e educando, ficando o ensino-aprendizagem muitas vezes sem sentido e em segundo plano (ALBUQUERQUE, 2015; PAES, 2015; VIEIRA, 2015).

A estrutura montada que engloba o Sistema Socioeducativo não é boa e converge, direta ou indiretamente, para a manutenção da própria violência gestada historicamente na dinâmica produtiva do capitalismo no Brasil, na qual educadores e a própria educação pública são desvalorizados (SOUZA JUNIOR; BITENCOURT; TRIGINELLI, 2017), afetando a trajetória escolar e social de adolescentes (PADOVANI; RISTUM, 2013). Grande parte dos educadores responsáveis pela educação dos adolescentes em conflito com a lei, principalmente dentro de unidade de internação, não está capacitada profissionalmente para o trabalho que se exige, e os que lá estão enfrentam dificuldades de toda a espécie, sobretudo ausência de instrumentos para sua capacitação e oportunidades de formação continuada; dificuldade de apoio dos serviços públicos, inclusive daqueles que deveriam compor a rede de atenção prevista pelo SINASE (BRASIL, 2012); falta de organização e de trabalho em equipe, além de incoerências em contratações terceirizadas realizadas por indicações políticas, tendo um fluxo de entrada e saída muito grande desse tipo de perfil, de modo a ampliar as dificuldades de integração e de articulação de diferentes atores e setores que demandam o trabalho socioeducativo (BERNARDO, 2011; FRANCISCO, 2017). Essas ocorrências inviabilizam o ensino, ao que se soma o fato de que o calendário escolar e a carga horária não são cumpridos e muitos dos professores não suportam ministrar aula nesses espaços (BARROS, 2015).

Ademais, há uma carência do tipo de educador que se aproxime dos adolescentes em uma relação dialógica e que consiga transmitir um sistema de regras que leve ao consenso e ao respeito (PIAGET, 1994), que busque entender e considere, nas normas de conduta e no 
disciplinamento, o universo cultural periférico e os hábitos específicos de grupos infratores e resistentes que são, dada a história de vida difícil que enfrentaram e enfrentam. Para Bernardo,

[...] é imprescindível olhar o profissional (sócio)educador e capacitá-lo continuamente para sua função que deve focar a educação, a ressocialização, o alcance da subjetividade do adolescente, e conduzi-lo à uma reflexão sobre sua transgressão a partir de um reordenamento de valores e condutas. Deste modo, os profissionais podem agir diretamente na (trans)formação dos adolescentes almejando o alcance da cidadania, dos direitos e deveres desta parcela da população e, por conseguinte, trabalhar para um convívio pacífico e reflexivo entre os membros de uma sociedade democrática. (BERNARDO, 2011, p. 165).

A construção de um espaço de reprovação da conduta deve prezar por uma convivência que propicie alternativas e inovações interdisciplinares (BEHR, 2016), focadas no fazer e no pensar, de maneira a aumentar as chances de êxito da ação socioeducativa e dirimir os conflitos (PAES, 2015). E isso não será alcançado se se deixar de investir na formação dos profissionais envolvidos, provendo os recursos materiais e financeiros para respaldar um trabalho de qualidade para a convivência dos jovens na sociedade. Não se pode deixar de consignar que estar no espaço socioeducativo, sobretudo em unidades de internação, é se colocar em uma posição desafiadora que é suscetível à violência criada e reproduzida pelos envolvidos da comunidade socioeducativa, inclusive por parte dos próprios atendidos (BERNARDO, 2011).

Assim, diferentemente do que é difundido no senso comum, que as medidas socioeducativas são espaços de muitos privilégios e impunidade, constata-se em diferentes pesquisas o contrário: um excesso de rigor na execução da socioeducação, com características sistêmicas de exclusão e de manutenção de hábitos criminosos conflitando com a concepção de proteção integral (BARROS, 2015; MEDEIROS, 2015; BORBA; LOPES; MALFITANO, 2015). Segundo Lasaretto (2009), as relações conflitantes e instáveis, próprias das incoerências do sistema, tendem a fazer com que os jovens fiquem ainda mais resistentes, violentos e indisciplinados, influenciados pelas suas tribos, que compartilham interesses comuns dentro da socialização criminosa de que fazem/faziam parte. A socialização de jovens infratores é própria de uma convivência dentro de um processo de "exclusão includente" recorrente no dia a dia, de auto reconhecer-se na relação com os outros marginalizados que compartilham experiências em situações semelhantes (LASARETTO, 2009) e que estabelecem hierarquias para decisões contra ou a favor da instituição.

É preciso superar essa pactuação transgressora e mobilizar o coletivo para um projeto educativo comum (FRANCISCO, 2017), que lhe faça frente também do ponto de vista dos jovens. A cultura arraigada na execução de medida socioeducativa, historicamente, corrobora para o fracasso educativo e inviabiliza a eficácia da inclusão social, quando esgotado o tempo 
da medida socioeducativa (MARINHO, 2013; VIEIRA, 2015). No campo da educação escolar, na intersecção com os programas de medidas socioeducativas, é preciso defender e reconhecer que o "pior aluno" precisa estar na melhor escola, com os melhores professores e recursos disponíveis, e não fora/excluído dessa importante instituição educativa. Dito de outro modo, precisa-se ofertar na educação desses grupos juvenis, independentemente do local socioeducativo, condições que promovam inclusão e referências de afeto, alegria, determinação, conhecimento e disciplina (LASARETTO, 2009), que a eles sejam também ofertados os conhecimentos necessários para serem capazes de produzir e de usufruir dos bens sociais e culturais historicamente postos pela humanidade. Para Manacorda,

[...] diante das exigências do mundo moderno, nós precisamos mirar o mais possível
na preparação do aluno não somente para ser ele mesmo, mas também para entrar na
sociedade, senão com a capacidade de ser um produtor de cultura em todos os campos,
pelo menos para ter a capacidade de desfrutar, de saber gozar, de todas as
contribuições da civilização, das artes, das técnicas, da literatura. A cultura deve ser
direcionada para todos, facilitando as disposições intelectuais e ao mesmo tempo
forçando todo mundo, com firme doçura a aprender e a participar de todos os prazeres
humanos. (MANACORDA, 2006 apud NOSELLA; LOMBARDI; SAVIANI, 2007,
p. 23).

Na prática, há uma contradição entre a necessidade de oferta educativa e o fenômeno punitivo/restritivo (COSTA JUNIOR, 2012; MEDEIROS, 2015), tanto nas escolas dos adolescentes em liberdade, quanto nos espaços de unidades de internação. A diferença entre essas duas realidades é que há um agravante na unidade de internação, dada a cultura punitiva, menorista e carcerária, alinhada à escassez de recursos materiais e financeiros, bem como um conduto processual de responsabilidade do Ministério Público e do Poder Judiciário, pois estes costumam se omitir diante dos fatos: predominam nas unidades de internação as ações dos agentes de segurança, os quais imprimem um controle punitivo que restringe o acesso do aluno à sala de aula por motivo de indisciplina (FRANCISCO, 2017). Nesse contexto, está imbricada uma coexistência do modelo repressivo e do educativo (ALBUQUERQUE, 2015; MESESES, 2006; MEDEIROS, 2015; VIEIRA, 2015), em que há a necessidade de fortalecer o caráter pedagógico de uma educação com disciplina, voltada à assimilação de conteúdos e de habilidades técnicas, acoplada à participação comunitária e familiar no processo socioeducativo. As incoerências da injusta distribuição de direitos fortalecem a pactuação criminosa e as crises geradoras de rebeliões e de fugas do sistema (FRANCISCO, 2017; MARINHO, 2013). Consoante Barros: 
Percebe-se que, embora a medida socioeducativa tenha legalmente conteúdo pedagógico, diferindo assim da noção de pena, na realidade trata-se em muitos casos da reprodução do sistema penal adulto, com raras exceções. Diante disso, os documentos assumem o tom de denúncia e relatam um sistema socioeducativo ineficaz que desrespeita, viola e pune constantemente, não cumprindo assim sua função social, ou seja, a oferta de execução pautada nos valores pedagógicos e nos direitos humanos. (BARROS, 2015, p. 139).

Em verdade, existe uma situação generalizada, amarga e reproduzida dentro de unidades de internação no Brasil, que foi objeto de pesquisa de Albuquerque (2015) na cidade de Brasília. De acordo com a autora,

[...] há a submissão das questões educacionais às questões de segurança, de modo que a gestão escolar desenvolve uma relação de subordinação para com a gerência de segurança da Unidade. A realidade educacional da Unidade é marcada por contradições e dificuldades oriundas da reprodução da vida material e inserida no movimento dialético da unidade dos contrários. São determinações do objeto estudado: a punição/a educação, a contenção na cela/a formação na escola, o formal/o real, a articulação/a centralização, as relações democráticas/as relações hierarquizadas, os interesses coletivos/o corporativismo. (ALBUQUERQUE, 2015, p. 166).

Nessa mesma direção, utilizando referenciais foucaultianos para compreender as normativas e o governo de jovens em conflito com a lei no Brasil, Caffagni assinala que

[...] há uma tendência geral em direção ao esvaziamento do conteúdo pedagógico das intervenções sobre os adolescentes em conflito com a lei. [...]. As práticas voltadas à aquisição de saberes, de apreensão de conteúdos são cada vez mais raras. [...]. O esvaziamento da escola no sistema socioeducativo é uma opção, é uma estratégia administrativa. [...]. Preferiu-se que os jovens fossem poupados dessa atividade disciplinar para que se minimizasse a resistência dos jovens às atividades socioeducativas. Tal política tem como objetivo reduzir os riscos e os gastos do sistema. (CAFFAGNI, 2012, p. 137-139).

Desse modo, o que fica em relevo, na dialética dos contrários, é a precarização da trajetória escolar desses alunos-socioeducandos, em um modelo de gestão escolarsocioeducativo centralizador, em detrimento da aquisição de conteúdos escolares e da participação colegiada, intersetorial e democrática na gestão da socioeducação (ALBUQUERQUE, 2015), além da pouca fiscalização do Ministério Público sobre as formas que são conduzidas e estruturadas as medidas socioeducativas, mormente no regime fechado (MENESES, 2006; FRANCISCO, 2017).

Importa destacar ainda que, nas etapas do trabalho sistêmico na socioeducação, não é comum a existência de programas de acompanhamento de egressos, os quais, findo o prazo de cumprimento da medida socioeducativa, voltam ao mesmo ambiente estigmatizante e precário dos pontos de vista econômico-cultural e de atenção familiar, sem suporte de políticas setoriais básicas no município. Nessa descontinuidade de atendimento, percebe-se um aumento de reincidências. É urgente, portanto, a criação de programas de acompanhamento de egressos no 
território brasileiro (MARINHO, 2013). O depoimento de uma egressa desse sistema explicita a falta de suporte do Estado, em forma de política pública, após o cumprimento da sentença:

[...] se eu quiser voltar a fazer o que eu fazia eu vou voltar com a certa... com a certa, é, tipo assim, com o medo de ir presa, né. Como sempre foi. [...] Se é pra se ressocializar lá não sei das quanta, vai pra quem quer, entendeu, pra quem não sustenta a bomba, porque se eu tiver precisando e ter que fazer alguma coisa eu vou fazer mesmo. Com o cuidado de não ir presa, entendeu... [...] eu quero é ter que esquecer aquele povo de lá [das medidas socioeducativas], que eu já passei ali também, tipo esquecer tudo. E que, a quem me prometeu um trabalho, tá, já que tá sendo gravado, me dá mesmo um trabalho, tá gente? Não só promete, cumpre. O povo lá eles promete muito pra pessoa lá ficar tranquila mas quando sai no final, não tá nem aí. [...] (KB). (MARINHO, 2013, p. 117-118, grifos do autor).

Na complexidade das vivências desses sujeitos, que estão em busca de autenticidade, desejos, sonhos e inquietações próprios da adolescência, tem-se efetivamente comprovado uma reiteração de infrações (MENESES, 2006), geradas nessas contradições do próprio sistema, que não consegue se fortalecer nas diferentes frentes e tempos do trabalho. A precarização não é natural, mas política e ideológica (MEDEIROS, 2015).

É preciso avançar na prática e mudar essa cultura. Diante dos avanços e dos recuos na política de atendimento socioeducativo (CAFFAGNI, 2012; BARROS, 2015; MEDEIROS, 2015), nas suas diferentes modalidades, é necessário apostar em metodologias inovadoras, progressistas e desafiadoras, mesmo em presença de um cenário determinante que aponta para a repressão e para as ações coercitivas na reprovação da conduta transgressora, inclusive de ordem jurídica (MENESES, 2006). A estrutura (re)produtora de violência, que influi na administração desse sistema, é gestada nos movimentos do capitalismo (da luta de classes e dos interesses antagônicos) (MEDEIROS, 2015; VOLPI, 2015), em um campo de atuação aberto no embate entre os subalternos e as elites, que disputam recursos e espaços de agenciamento dentro do aparelho do Estado (BOURDIEU, 2014; SOUZA, 2009) e a hegemonia do tipo de funcionamento e de tratamento ofertado na política socioeducativa. Cabe fazer valer um engajamento interinstitucional a serviço do bem-estar, da ampliação de direitos e da efetividade no redirecionamento social (ALBUQUERQUE, 2015; CAFFAGNI, 2012), evitando a naturalização da repressão e da punição (MENESES, 2006).

A substituição, na história recente, da "pena" na situação irregular de "menores" para o direcionamento socioeducativo da proteção integral aos adolescentes e aos jovens inimputáveis representa um garantismo jurídico e processual (BERNARDO, 2011; BARROS, 2015). Contudo, isso é suficiente e tem adesão no sistema de justiça, ou se trata apenas de um eufemismo terminológico? (MENESES, 2006). 
As formas de fortalecer-se o Sistema Socioeducativo, tendo em tela as microrrelações e os limites da política socioeducativa, imersa nas contradições sociais mais amplas, dependem (em grande medida) do processo de apuração das infrações e dos estudos de cada caso que levem ao entendimento das circunstâncias infracionais, visando colaborar com relatórios técnicos e procedimentos processuais novos que possam subsidiar o Poder Judiciário na aplicação da melhor medida socioeducativa e dos mais adequados encaminhamentos necessários para inclusão dos jovens nos serviços setoriais disponíveis e, por vezes, negligenciados no município (LIMA, 2013)

Esses são instrumentos que podem ser utilizados até mesmo de modo preventivo, sobretudo nos casos das infrações mais brandas, fazendo da educação o investimento para as mudanças de atitudes infracionais (LIMA, 2013). Nessa perspectiva, com trabalho árduo, colaborativo e criterioso, pode-se reduzir as violações dos direitos previstos, bem como retrair o entendimento difundido de que o termo "socioeducativo" se trata de puro eufemismo. Segundo Caffagni:

Deve-se considerar três coisas na escolha da medida jurídica: a gravidade, as circunstâncias da infração e a capacidade do jovem em cumprir com as determinações da justiça. $\mathrm{O}$ critério da capacidade está vinculado à análise das condições efetivas e individuais do processo de desenvolvimento do adolescente. As necessidades particulares derivadas do processo de formação pelo qual passa o acusado devem ser consideradas para que se possa planejar adequadamente a resposta socioeducativa. (CAFFAGNI, 2012, p. 134, grifos do autor).

Se bem organizado esse processo, as chances de, lá na frente, ser possível auxiliar a gestão escolar e não escolar das medidas socioeducativas são muito grandes, pois a equipe pedagógica estará munida de informações necessárias para compreender quem é esse sujeito adolescente, colaborando na elaboração do Plano Individual de Atendimento (PIA) (ALBUQUERQUE, 2015), que projete um percurso na direção da liberdade, garantindo-se que o setor da segurança viabilize o previsto nas orientações da coordenação pedagógica (FRANCISCO, 2017; MARTINS, 2016). Toda essa dinâmica, já na execução da medida com a vênia dos aplicadores do direito, só tem sentido e significado se for interdisciplinarmente avaliada e acompanhada de perto pelo Ministério Público e Poder Judiciário, como prevê o SINASE.

Para além da leitura técnica de relatórios, essa presença pode coibir as diferentes agressões físicas e violações jurídicas (MENESES, 2006), em decorrência do fortalecimento do garantismo integrado entre instituições e setores desse complexo sistema. Faz-se necessário também, para o bom andamento das atividades socioeducativas, viabilizar o fluxo de 
atendimento da medida, considerando a vida do adolescente para a liberdade, e, mesmo no caso de internação, proporcionar maneiras de estreitar a convivência e os vínculos familiares, o que exige o cumprimento da sentença próximo da residência de origem do adolescente (FRANCISCO, 2017; MEDEIROS, 2015). Com o devido apoio e fortalecimento familiar, temse uma maior abertura e comprometimento do adolescente com as atividades educativas e culturais propostas pelo PIA.

Nessa interpretação, procurando identificar a natureza pedagógica dos operadores do direito na apuração de infrações, na aplicação e na execução das medidas socioeducativas, Meneses (2006), promotor de justiça no estado do Rio Grande do Sul, assinala que:

Se o sistema de justiça for lento [...] não haverá garantismo. Talvez alguns defendam a existência de um garantismo jurídico, na medida em que a adequação típica (ato contrário à norma) teve resposta estatal, contemplando as formalidades de um processo penal juvenil, ou infracional, onde figuraram todos os personagens a que a lei atribui papéis. Mas, sob o prisma pedagógico, o retardamento da internalização da norma compromete a disciplina e a construção de valores e o garantismo jurídico cairá na retórica defesa do cumprimento da lei pelos operadores da justiça. Diferente não será se a execução das medidas socioeducativas estabelecer uma relação meramente formal, de cumprimento de atividades pelas atividades, sem que se permita passear pelo familiar, social e psicológico do adolescente infrator [...]. Os resultados apurados em pesquisa feita com promotores de justiça gaúchos, salvo algumas exceções, dão mostras de que muito longe estamos da implementação do compromisso com a dimensão pedagógica, presos ainda ao histórico compromisso penal, onde cabe ao agente do Ministério Público conceder remissão ou representar contra o adolescente, para obtenção de uma sanção, que se satisfaz pela execução fiscalizada em verificação de documentos. Mesmo que deva reconhecer que as inúmeras atribuições de um promotor de justiça e, porque não dizer, de um juiz de direito, por vezes remetem a sérias intervenções em outras matérias de seu cotidiano institucional e forense, não poderia admitir a exclusão do sistema de justiça do artigo $4^{\circ}$ do Estatuto da Criança e do Adolescente, que determina absoluta prioridade à efetivação de direitos fundamentais, entre eles a educação [...]. (MENESES, 2006, p. 153-154).

Por conseguinte, o trabalho interinstitucional e intersetorial, com predominância do fazer pedagógico na proteção integral, necessita ter respaldo dos dirigentes das medidas socioeducativas, dos principais integrantes institucionais do sistema e da presença participativa da família, o que tem maior potencial nas medidas de meio aberto (Liberdade Assistida e Prestação de Serviço à Comunidade). É preciso que se formulem conceitos que atravessem as disciplinas e que se efetivem uma agilidade processual centrada nos preceitos do ECA e do SINASE, para se aproximar dos complexos e necessários objetivos da socioeducação (MENESES, 2006; MEDEIROS, 2015; VOLPI, 2015). 


\section{Considerações finais}

Em síntese, diante do exposto nas linhas anteriores, podem-se destacar três aspectos: I. a variedade de universidades e orientadores imbricados em pesquisas na Pós-Graduação que envolvem a situação de jovens em conflito com a lei e submetidos a medidas socioeducativas; II. o viés empírico e qualitativo das pesquisas publicadas, tanto em revistas qualificadas pela área de Educação na CAPES quanto em dissertações e teses; e III. os resultados que apontam fragilidades familiares e problemáticas escolares como situações de vulnerabilidade associadas ao crescimento dos atos infracionais.

De fato, constatou-se uma variedade de produtos provenientes das universidades públicas, com destaque para a UnB, Unesp, USP, UFRGS, UFSCar e UFRN. Das instituições privadas, o conjunto das PUCs avulta pela quantidade de publicações, podendo-se aventar aqui o interesse de setores da igreja católica na temática, um ator importante nesse âmbito, no Brasil. Ainda, há também uma quantidade significativa de orientadores que são referências nesse campo.

As pesquisas sobre Sistema Socioeducativo têm tido maior recepção na área de Psicologia, área bastante voltada à adolescência; seguida pelo Serviço Social, que tem, nos serviços socioassistenciais que envolvem o cuidado com os adolescentes pobres em geral, um campo de ação profissional; e pela área da Educação - afinal; a escola regular e a educação não-escolar são questões recorrentes no entorno das preocupações com o adolescente tido como autor do ato infracional.

Em relação aos artigos científicos, obteve-se 91 publicações sobre a temática, o que denota a relevância acadêmica de questões postas pelo Sistema Socioeducativo, além da necessidade social de se apresentar proposições consistentes para a situação de crise que vive o funcionamento da justiça juvenil brasileira e para ações socioeducativas eficazes, tanto para a sociedade quanto para as diferentes juventudes. A maioria dos estudos tem um caráter prático e percorre um caminho em torno da busca da compreensão analítica do fenômeno, o que evidencia certa dificuldade na formulação de postulados mais universais em referência à temática, salvo a correlação sempre presente entre pobreza e situações de vulnerabilidade social (CASTEL, 1999).

Do ponto de vista da análise dos resultados apresentados nos produtos reunidos, estes se concentram na relação entre a escola, a família e o ato infracional, atrelada ao contexto de desigualdade estrutural em que se inserem e às já referidas vulnerabilidades associadas, fatores que comprometem a permanência na escola e fazem com que se perca o sentido do processo 
educativo formal. Acoplado a essas situações e tendo em vista que grande parte dos adolescentes é proveniente das classes trabalhadoras mais pobres e com poucas chances de ostentar bens materiais pelo consumo legal, os jovens encontram no comércio ilegal um caminho para algum "acesso", o que tem aumentado a quantidade de sentenças e de ingressos no Sistema Socioeducativo.

No quadro da complexidade dos delitos, os resultados deste Estudo da Arte permitem inferir a necessidade de fomentar as investigações e as reflexões sobre as temporalidades das ações interinstitucionais e setoriais do Sistema Socioeducativo, das perspectivas educativas dos Planos Decenais de Atendimento Socioeducativo, do processo de avaliação e de acompanhamento da política de execução socioeducativa e dos programas de egressos. A socioeducação é, assim, um campo aberto à pesquisa e que carece menos de subsídios teóricos e mais de práticas que implementem preceitos já postos e que possam, então, ser avaliadas.

Por fim, vale destacar a relevância de ampliar as pesquisas acerca do que propõe e do que, de fato, vem acontecendo no SINASE, com vistas a trazer aportes para se resolver as situações de crise que vivem os estados brasileiros: rebeliões, fugas, assassinatos e instalações do crime organizado nas unidades socioeducativas, inclusive considerando o que vem sendo indicado pela atual gestão do executivo federal no que diz respeito à questão da redução da idade penal e às medidas de ampliação de armamento e de repressão militar. Igualmente, sem descurar do que estabelece a Constituição Federal, o Estatuto da Criança e do Adolescente e a lei que instituiu o Sistema Nacional de Atendimento Socioeducativo, pois é disso que precisa uma sociedade comprometida com a redução das violências, das infrações e do aprisionamento exacerbado que inviabiliza a (re)educação para a cidadania e para a convivência. 


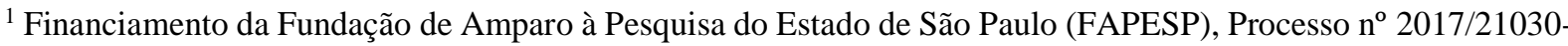
6 e Processo BEPE $n^{\circ}$ 2019/00396-8. Insta registrar e agradecer o apoio fundamental da FAPESP para o desenvolvimento dos projetos de pesquisa na temática do Sistema Socioeducativo, com destaque para a possibilidade de discutir a realidade do sistema brasileiro no estágio de pesquisa no exterior, realizado no Conservatoire National des Arts et Métiers (CNAM), Paris - França, contribuindo para novas experiências, reflexões, análises e produções.

${ }^{2}$ Qualis é o conjunto de procedimentos utilizados pela Capes para estratificação da qualidade da produção intelectual dos Programas de Pós-Graduação no Brasil (http://www.capes.gov.br).

${ }^{3}$ Seguindo uma formulação feita em estudo anterior, coordenado pela Profa. Marília Sposito (2009).

${ }^{4}$ Vale destacar que omissões podem ter sido feitas, principalmente por motivos referentes aos parâmetros de busca, que podem não ter abarcado dissertações e teses no banco de dados do IBCTI que se voltassem para a temática, ou mesmo por imperfeições no levantamento, diante do volume de textos encontrados. Mesmo assim, algumas escolhas de seleção se impuseram. Destarte, muito ainda precisa ser analisado e discutido, com vistas a proposições práticas, haja vista a complexidade da temática e as crises que enfrentam os diferentes sistemas socioeducativos dos estados brasileiros.

${ }^{5}$ Os periódicos e o número de artigos encontrados foram: Cadernos de Pesquisa (7), Educação em Revista (5), Educação e Pesquisa (4), Educação \& Sociedade (4), Ensaio: Avaliação e Políticas Públicas em Educação (3), Revista Bolema (3), Revista Brasileira de Ciências Sociais (2), Estudos Feministas (2), Pro-posições (1), Educação Temática Digital (1), Revista Brasileira de Educação (1).

${ }^{6}$ Sobre a tendência tradicional, insta destacar, em acordo com Martins (2016, p. 52), que "[...] o conhecimento é entendido como algo pronto e acabado, como algo essencial e, portanto, deve ser identificado, sistematizado e transmitido para ser contemplado".

${ }^{7}$ Não há consenso do que seja exatamente esse "pós", mas faz-se uma crítica ao modo moderno de vida e sua adaptação ao capitalismo, homogêneo, racional, positivista, tecnocêntrico, que tende a uma universalização e globalização progressiva e linear (HARVEY, 2017).

${ }^{8}$ Foram referenciados somente os trabalhos citados no corpo deste artigo, tendo em vista a exiguidade de espaço.

\section{Referências}

ALBUQUERQUE, Liana Correia Roquete de. A gestão escolar na promoção do direito à educação de adolescentes privados de liberdade - DF. 2015. 175 f. Dissertação (Mestrado em Educação) - Universidade de Brasília, Brasília, 2015.

BARROS, Aline Menezes de. Escolarização de adolescentes em cumprimento de medida socioeducativa de internação: estudo bibliográfico. 2015. 184 f. Dissertação (Mestrado em Educação) - Universidade do Estado do Rio de Janeiro, Rio de Janeiro, 2015.

BEHR, Mariana Torres. Ressignificando o papel do educador no contexto das medidas socioeducativas. 2016. 150 f. Dissertação (Mestrado em Educação) - Universidade de Brasília, Brasília, 2016.

BERNARDO, Julia Ferreira. Competência moral e perfil de profissionais que atendem adolescentes em conflito com a lei. 2011. 175 f. Dissertação (Mestrado em Educação) Universidade Estadual Paulista, Marília, 2011.

BORBA, Patrícia Leme de Oliveira; LOPES, Roseli Esquerdo; MALFITANO, Ana Paula Serrata. Trajetórias escolares de adolescentes em conflito com a lei: subsídios para repensar políticas educacionais. Ensaio: Avaliação e Políticas Públicas em Educação, Rio de Janeiro, v. 23, n. 89, p. 937-963, dez. 2015. DOI: http://dx.doi.org/10.1590/S010440362015000400006 
BOURDIEU, Pierre. Sobre o Estado: cursos no Collège de France (1989 - 1992). Edição estabelecida por Patrick Champagne. Tradução de Rosa Freire d'Aguiar. São Paulo, SP: Companhia das Letras, 2014.

BRASIL. Decreto $N^{\circ} 17.943-A$, de 12 de outubro de 1927. Consolida as leis de assistencia e protecção a menores. Rio de Janeiro: Presidência da República, Casa Civil, Subchefia para Assuntos Jurídicos, [1927]. Disponível em:

http://www.planalto.gov.br/ccivil_03/decreto/1910-1929/d17943a.htm. Acesso em: 21 dez. 2018.

BRASIL. Lei $N^{o}$ 6.697, de 10 de outubro de 1979. Institui o Código de Menores. Brasília: Presidência da República, Casa Civil, Subchefia para Assuntos Jurídicos, [1979]. Disponível em: http://www.planalto.gov.br/ccivil_03/leis/1970-1979/L6697.htm. Acesso em: 23 jan. 2019.

BRASIL. Lei No 8.069, de 13 de julho de 1990. Dispõe sobre o Estatuto da Criança e do Adolescente e dá outras providências. Diário Oficial da União: seção 1, Brasília, DF, n. 135, p. 13563, 16 jul. 1990. BRASIL. Lei $N^{o} 12.594$, de 18 de janeiro de 2012. Institui o Sistema Nacional de Atendimento Socioeducativo (Sinase), regulamenta a execução das medidas socioeducativas destinadas a adolescente que pratique ato infracional; e altera as Leis $\mathrm{n}^{\text {o }} \mathrm{s} 8.069$, de 13 de julho de 1990 (Estatuto da Criança e do Adolescente); 7.560, de 19 de dezembro de 1986, 7.998, de 11 de janeiro de 1990, 5.537, de 21 de novembro de 1968, 8.315, de 23 de dezembro de 1991, 8.706, de 14 de setembro de 1993, os Decretos-Leis $\mathrm{n}^{\circ} \mathrm{s} 4.048$, de 22 de janeiro de 1942, 8.621, de 10 de janeiro de 1946, e a Consolidação das Leis do Trabalho (CLT), aprovada pelo Decreto-Lei $n^{\circ}$ 5.452, de $1^{\circ}$ de maio de 1943. Brasília: Presidência da República, Casa Civil, Subchefia para Assuntos Jurídicos, [1912]. Disponível em: http://www.planalto.gov.br/ccivil_03/_Ato2011-2014/2012/Lei/L12594.htm. Acesso em: 7 fev. 2019.

BRASIL. Presidência da República. Secretaria Especial dos Direitos Humanos. Conselho Nacional dos Direitos da Criança e do Adolescente. Sistema Nacional De Atendimento Socioeducativo - SINASE. Brasília: CONANDA, 2006.

CAFFAGNI, Lou Guimarães Leão. Técnicas pedagógicas do sistema socioeducativo proposto pelo ECA: uma análise das novas instituições de responsabilização juvenil a partir da filosofia de Michel Foucault. 2012. 152 f. Dissertação (Mestrado em Educação) Universidade de São Paulo, São Paulo, 2012.

CASTEL, Robert. As metamorfoses da questão social: uma crônica do salário. 2. ed. Petrópolis: Vozes, 1999.

CONTE, Marta. Desafios na Juventude: drogas, consumismo e violência. Educação \& Realidade, Porto Alegre, v. 33, n. 2, p. 131-146, jul./dez. 2008.

COSTA JUNIOR, Reinaldo Vicente da. Tá em casa ou na escola? Uma leitura da prática escolar em unidade de internação socioeducativa da cidade de São Paulo. 2012. $181 \mathrm{f}$. Dissertação (Mestrado em Educação) - Universidade Nove de Julho, São Paulo, 2012. 
FRANCISCO, Julio Cesar. Processos educativos não-escolares: um estudo em unidade de internação no estado do Ceará. 2017. 159 f. Dissertação (Mestrado em Educação) Universidade Federal de São Carlos, São Carlos, 2017.

HARVEY, David. Condição pós-moderna: uma pesquisa sobre as origens da mudança cultural. 26. ed. São Paulo: Edições Loyola, 2017.

LASARETTO, Lucilaine Nunes. Tribos de adolescentes em situação de medida sócioeducativa: um estudo analítico-descritivo. 2009. 136 f. Dissertação (Mestrado em Educação Escolar) - Universidade Estadual Paulista "Júlio de Mesquita Filho", Araraquara, 2009.

LIMA, Agnaldo Soares. Guia para implantação do atendimento inicial ao adolescente a quem se atribui autoria de ato infracional. Brasília: Editora Dom Bosco, 2013.

LUKÁCS, György. Para uma ontologia do ser social. São Paulo: Boitempo, 2013.

MARINHO, Fernanda Campos. Jovens egressos do Sistema Socioeducativo: desafios à ressocialização. 2013. 149 f. Dissertação (Mestrado em Psicologia) - Universidade de Brasília, Brasília, 2013.

MARTINS, Marcos Francisco. Educação não-escolar: discussão terminológica e mapeamento dos fundamentos das tendências. Revista Contrapontos, Itajaí, v. 16, n. 1, p. 40-61, 2016. DOI: http://dx.doi.org/10.14210/contrapontos.v16n1.p40-61

MEDEIROS, Fernanda Cavalcanti de. A inserção da família no processo socioeducativo de adolescentes em privação de liberdade. 2015. 188 f. Dissertação (Mestrado em Psicologia) Universidade Federal do Rio Grande do Norte, Natal, 2015.

MESESES, Elcio Resmini. O Ministério Público e as medidas socioeducativas: uma reflexão jurídico-pedagógica. 2006. 171 f. Dissertação (Mestrado em Educação) - Universidade Federal do Rio Grande do Sul, Porto Alegre, 2006.

NOSELLA, Paolo; LOMBARDI, José Claudinei; SAVIANI, Demerval. Mario Aligheiro Manacorda: aos educadores brasileiros. Campinas: Unicamp/HISTEDBR-FE/CNPq, 2007.

PADOVANI, Andréa Sandoval; RISTUM, Marilena. A escola como caminho socioeducativo para adolescentes privados de liberdade. Educação e Pesquisa, São Paulo, v. 39, n. 4, p. 969 984, 2013. DOI: http://dx.doi.org/10.1590/S1517-97022013005000012

PAES, Paulo Cesar Duarte. Educação de adolescentes privados de liberdade: uma abordagem vigotskiana. Inter-Ação, Goiânia, v. 40, n. 2, p. 253-268, 2015. DOI:

https://doi.org/10.5216/ia.v40i2.32818

PIAGET, Jean. O juízo moral da criança. São Paulo: Summus, 1994.

RIZZINI, Irene. A criança e a lei no Brasil: revisitando a história (1822-2000). Brasília:

UNICEF; Rio de Janeiro: USU Ed. Universitária, 2000. 
SENNETT, Richard. Respeito: a formação do caráter em um mundo desigual. Rio de Janeiro: Record, 2004.

SILVA, Carmem Andrea. Trajetórias de jovens em conflito com a lei em cumprimento das medidas socioeducativas em Belo Horizonte. 2003. 119 f. Dissertação (Mestrado em Educação) - Universidade Federal de Minas Gerais, Belo Horizonte, 2003. SOUZA, Jessé. Ralé brasileira: quem é e como vive. Belo Horizonte: Editora da UFMG, 2009.

SOUZA JUNIOR, Hormindo Pereira de; BITENCOURT, Celeste Deográcias de Souza; TRIGINELLI, Daniel Handan. Educação e violência: uma reflexão a partir da ontologia do ser social. Pro-Posições, Campinas, v. 28, n. 1, p. 103-124, abr. 2017. DOI: http://dx.doi.org/10.1590/1980-6248-2015-0044

SPOSITO, Marilia Pontes. Juventude e Educação: interações entre educação escolar e educação não-formal. Educação \& Realidade, Porto Alegre, v. 33, n. 2, p. 83-97, jul./dez. 2008.

SPOSITO, Marilia Pontes. O Estado da Arte sobre juventude na pós-graduação brasileira: Educação, Ciências Sociais e Serviço Social (1999-2006). Belo Horizonte: Argumentum, 2009.

VIEIRA, Márcia Marques. A socioeducação na percepção do agente socioeducador: um estudo no Distrito Federal. 2015. 121 f. Dissertação (Mestrado em Psicologia) - Universidade Católica de Brasília, Brasília, 2015.

VOLPI, Mario. O adolescente e o ato infracional. São Paulo: Cortez, 2015. 